\title{
ACTIVATION AND THE RELATION BETWEEN CONTEXT AND GRAMMAR
}

\author{
Daniel García Velasco
}

\begin{abstract}
Functional Discourse Grammar is characterized as the grammatical component of a wider theory of verbal interaction and is linked to two adjacent components: The Conceptual and the Contextual Components. One general property of these components is that they are not open-ended, but are said to contain only that extra-linguistic information which is relevant for the construction and interpretation of the immediate linguistic expression. In this contribution I explore the relation between context and grammar and I conclude that the FDG's requirement that the Contextual Component should only contain those features which have a systematic impact on grammar is too strict. In particular, I claim that the Contextual Component is relevant in linguistic usage through speakers' mental representation of its contents, which could be captured in the Conceptual Component. I further argue that the notions of 'activation' and 'sharedness' are relevant to understanding the motivation of two syntactic processes, subject raising and extraction from NPs, and should therefore find a place in the model even if they do not always lead to systematic effects. It is finally proposed that these pragmatic dimensions could find their way into the grammar by means of unmarked pragmatic configurations or content frames.
\end{abstract}

Keywords: Functional Discourse Grammar; Activation; Givenness; Context.

\section{Introduction 1}

In this contribution I intend to explore the relation between Activation and its morphosyntactic correlates in order to propose an adequate treatment for this category in Functional Discourse Grammar (Hengeveld and Mackenzie 2008; FDG). The paper is organised as follows: Section 2 claims that FDG falls short in its compatibility with a theory of verbal interaction and defends the need for another dimension of pragmatic organization which can account for the dynamic construction of discourse. In the third section, I argue that the notion of givenness is crucial to understanding the properties of that dimension and I introduce the notions of activation and sharedness. The next section presents two syntactic phenomena, raising and displacement from complex noun phrases, as examples of processes whose nature cannot be fully appreciated unless one

1 I am grateful to the editors of this special issue and the participants in the International Workshop on FDG (Barcelona, September 2011) for their comments on previous versions of this paper and for a very relevant and enriching discussion in the workshop sessions. Thanks are also due to Francis Cornish for corrections and valuable comments on the pre-final version. All remaining errors are my sole responsibility. 
takes a dynamic view on discourse construction and makes use of the proposed pragmatic dimensions. Finally, section 5 discusses the implications of the analysis for the theory of FDG.

\section{FDG, context and the dynamicity of verbal interaction}

Twenty years ago, Mackenzie and Keizer (1991) pointed out the difficulty in integrating a static grammar (Functional Grammar at the time) within a dynamic theory of verbal interaction. A theory of verbal interaction should take care of the dynamic real-time processes of speakers and addressees in the construction of discourse, whereas the grammar only represents the outcome of those processes rather than the processes themselves (Mackenzie and Keizer 1991: 170). Consequently, the authors argued, the relation between the static grammar and the dynamic theory of verbal interaction is inherently problematic.

FDG is defined as the grammatical component of a wider theory of verbal interaction. Even though some authors have tried to see the grammar as a dynamic system, Hengeveld (2004) has made it clear that this is not the right interpretation and has defended the view that FDG should be understood as a 'pattern model', pointing out that this is not in contradiction with the possibility of the grammar itself being dynamically implemented. The adjacent Contextual and Conceptual Components are thus not part of the grammar itself (and are indeed physically placed outside the grammar as discrete boxes), but are included in the theory under the belief that a full account of some grammatical phenomena may require information from these components. FDG captures relevant extra-linguistic aspects of verbal interaction in the outer components, thus keeping the grammar as a system which represents static structural patterns. It is fair to conclude, then, that the same problematic relation between the dynamic theory of verbal interaction and the static nature of the grammar which was identified by Mackenzie and Keizer for Functional Grammar also holds for FDG in spite of the explicit introduction of the two adjacent components.

A crucial aspect in this interaction is that the influence of context upon form must be systematic, in the sense that for certain contextual conditions to be considered relevant in linguistic analysis they should force regular choices or operations in the grammar. Thus, in Spanish, speakers are forced to choose between masculine and feminine forms and formal and informal address forms in contexts such as (1) on the basis of the addressee's sex, and the social relations among speech participants respectively, information which is obviously provided by the context (Hengeveld and Mackenzie 2008: 10):

$$
\begin{array}{lll}
\text { ¿Qué } & \text { pálid-a } & \text { est-ás! } \\
\text { What } & \text { pale-F.SG } & \text { COP-IND.PRS.2.SG.FAM } \\
\text { 'How pale you look!' } &
\end{array}
$$

If, on the contrary, contextual factors do not lead to systematic coding, but are expressed optionally, they will remain outside FDG's characterization of the relation between context and grammar. Thus, Hengeveld and Mackenzie (2008: 10) argue against Butler's (2008) view that the choice of lexical items based on the style or genre of the actual discourse is information that should be modelled in the Contextual 
Component (i.e. the informality of the English item kid vs child), given that this selection is not systematic (i.e. one can choose an informal lexical item in a formal context after all). It is no wonder then that Hengeveld and Mackenzie (2008: 9) state that the Contextual Component in FDG "makes no effort to offer anything like a complete description of the overall discourse context" (see Butler 2013 for a reaction to this criticism).

Hengeveld and Mackenzie (this issue) further argue that the Contextual Component covers two types of information: Discoursal and situational. Crucially, situational information is restricted to a "language-specific selection of those details of the speech situation that have relevance for Formulation" whereas discoursal information is recorded in the Contextual Component because it may be needed for anaphoric reference to aspects of previous utterances. What both dimensions have in common is that they are dynamic, in the sense that they are constantly updated and adapted to the needs of communication as the verbal interaction evolves.

This dynamic nature of the Contextual Component is illustrated in Hengeveld and Mackenzie (this issue) with respect to the availability of referents for anaphoric reference and for the assignment of pragmatic functions. The construction of discourse entails the constant change of participant roles and the development of a coherent and cooperative activity of language interaction in which objects, entities and pieces of information are introduced, talked about and finally disappear from the focus of attention. Hengeveld and Mackenzie (this issue) acknowledge that this dynamic nature of the context should also be covered in FDG's Contextual Component and link it to a 'time' dimension which also relates to the Given / New information distinction, in that as the discourse develops, the informational status of referents shifts from new to given. This is formally implemented through the notion of 'stacking' by which entities which are last mentioned in discourse occupy a prominent position in the Contextual Component and achieve a high degree of 'contextual saliency'. The authors stress that 'contextual saliency' should not be confused with the notion of 'activation', which belongs into the Conceptual Component.

However, there are two aspects of FDG's characterization of the relation between grammar and context that may be considered problematic. First, it is difficult to see how it could account for the inherent dynamicity of language use. Given that the influence of context on the optional choices available to speakers is not taken care of in the FDG conception of the Contextual Component, the theory's interpretation of 'context' is a 'static' one, in the sense that it operates on fixed characterizations of the setting in which a speech act takes place. Moreover, the properties of the Contextual Component are only determined after an analysis of the linguistic expression in question. Thus, in (1) the presence of the feminine gender suffix $-a$ should take the linguist to conclude that the addressee's sex should be specified as 'female' at the Contextual Component. ${ }^{2}$ The FDG view of context of an utterance is thus in practice a static photograph which contains those extra-grammatical aspects which may have direct influence upon the form of the linguistic expression. As pointed out to me by Lachlan Mackenzie (pc), however, the FDG approach to the dynamism of context could be seen as a sequence of states, in much the same way as the dynamism of a movie is the result of the rapid

${ }^{2}$ As pointed out to me by Evelien Keizer (pc) it might be more appropriate to say that the suffix takes the linguist "to indicate that the knowledge that the addressee's sex is female was part of the speaker's Contextual Component at the time of speaking”. Indeed, as I argue below, the speaker's knowledge could be understood as part of his mental context. 
succession of still photographs. Although I fully agree that, for modelling purposes, one is forced to provide static representations of the context that does not necessarily imply that it must be conceived of as a static entity. It also ignores the fact that those states, if they can be isolated at all, are crucially interwoven and it would be difficult to explain the properties of one without reference to the preceding or following states.

Moreover, the interpretation of the context as the transition from one static state to another static state entails that 'context' is an objective observable entity, which relates to a second problem in the FDG characterization of the Contextual Component. As argued by Connolly (2007: 18), it is necessary to distinguish between a mental and an extra-mental context. The former is "the part of the context that resides in the minds of the producers and the interpreters (including analysts) of a discourse or fragment, while the extra-mental context is supplied by the outside universe" (see also Connolly, this issue). What is crucial about the mental context is that "the only way in which contextual factors may directly affect the production and interpretation of discourse is through their presence in the mind of those individuals" (Connolly 2007: 19). In other words, if the FDG Contextual Component contains only those aspects of the context which are relevant in the production and interpretation of linguistic expressions, and if those are necessarily part of the speakers' mental context, it follows that the Contextual Component is a mental entity. By definition, a mental context should be speech participant bound, and although the different mental contexts of speech participants will tend to overlap, they are likely to be different in significant ways. This poses the question of (i) whose mental context is actually being modelled in FDG's Contextual Component, and (ii) the nature of the relation between the Contextual Component and the Conceptual Component. ${ }^{3}$

In order to illustrate the problem, consider example (1) again. Although the sex of the addressee, which determines the choice of the feminine suffix $-a$, may be seen as an objective observable fact of the linguistic setting, the social relation between the speech participants, which correlates with the tú/usted distinction, is certainly a matter of interpretation as different speakers holding similar social relations may choose one or the other for different reasons. For example, in Spain fifty years ago it was customary for students to address their teachers with the formal 'usted', whereas nowadays, and probably due to a relaxation of social class differences, they tend to use the informal form of address. Still many people believe that this recent tendency is socially unacceptable and would rather continue the old way, which shows that what really counts in linguistic usage is not the allegedly objective social relation between speakers and addressees, but the way it is conceived of by each speaker. ${ }^{4}$

Similarly, in the analysis of pragmatic functions FDG has concentrated on the formal impact that the notions Topic and Focus may have on linguistic expressions and are thus part of the grammar (although of course, certain conditions must be met in the Contextual Component for Topic of Focus function to be assigned to a linguistic unit). As mentioned earlier, the notions of Given and New information are linked to the

3 Alternatively, it could be argued that the Contextual Component in FDG is an idealized object which does not have objective existence, but this would certainly be a problem to meet the standard of psychological adequacy.

4 This problem extends to other notions such as that of 'contextual saliency', which Hengeveld and Mackenzie (this issue) distinguish from that of activation. Indeed, it is difficult to see how entities can be 'salient' if not through the speech participants' focussing their attention on them for communicative reasons. 
operation of stacking and assumed to belong into the Contextual Component. This essentially coincides with the view also expounded in Mackenzie and Keizer (1991) who argued that the dimensions Topic / Focus and Given / New are essentially different and cannot be combined in a set of pragmatic functions, as was the case in Functional Grammar (Dik 1997a). The crucial difference might be that Topic and Focus are identified on the basis of the formal impact on the grammar of languages, whereas Given / New relate to the status of referents and pieces of information in the mind of both speakers and addressees. It is no wonder, then, that the Given / New distinction is not included in FDG's set of pragmatic functions.

With all this in mind, I will next offer a characterization of Activation which essentially derives from the work of Chafe (1994) and Lambrecht (1994). I will try to show that givenness has formal impact both on the grammar of languages and on the discourse creating activity and that, therefore, its role should be reflected in the grammar.

\section{Identifiability, activation and givenness}

If ones assumes that the dynamicity of language use results from the constant change of the speech participants' mental states as reflected in their (mental) contexts and, as such, cannot be captured in a static function-to-form approach to the study of pragmatic functions, the emphasis shifts from the linguistic manifestation of Topic, Focus and related categories to the cognitive status of referents in the speakers' minds under the belief that these serve as the basis for the assignment of pragmatic functions in a given utterance.

The literature on the study of the mental representations of referents has identified two main categories: Identifiability and Activation (see Prince 1981; Chafe 1994; Lambrecht 1994). Given their cognitive nature (i.e. they are aspects of mental representations) and their dependence on extragrammatical factors (e.g. a referent visually perceptible in the communicative setting may be assumed to be identifiable for the speech participants), it would seem that the natural locus to capture these categories in FDG are the Conceptual and Contextual Components and not the grammar system. However, whereas identifiability is represented by operators at the Interpersonal Level (Hengeveld and Mackenzie 2008: 122; Smit 2007), FDG does not provide the means to signal the activation status of a referent in interpersonal representations. The reason may well be that even though activation correlates with well-known phonological and morphosyntactic properties (see section 4), it does not seem to receive systematic formal treatment in individual languages. This may be due, as Evelien Keizer has suggested to me, to the inherently gradual status of activation. Identifiability, on the other hand, is coded in the formal category (in)definiteness.

Following Chafe and Lambrecht, and simplifying somewhat, identifiable referents may be defined as those for which speakers and listeners share a mental representation, whereas active referents are those which are the focus of attention at a given point in the verbal interaction. In the words of Lambrecht (1994), identifiability refers to the knowing 5 of a referent and activation to the thinking about a referent. Activation is thus

5 Although, as pointed out to me by Evelien Keizer (pc), a more adequate description would be 'being aware of the existence of a referent' in order to include definite non-specific entities. 
a dynamic category as the focus of attention may shift from one referent to another in the course of the interaction. Identifiability, however, is more static; it depends upon the speaker's initial estimate of his/her addressee's general knowledge. Once a referent is introduced in discourse it becomes identifiable and active and, although it can be deactivated and reactivated in subsequent discourse, or by different participants, it is unlikely that it can be brought back to an unidentifiable state. Obviously, then, the characterization of activation as a cognitive mental notion poses a significant challenge for the FDG conception of the Contextual Component, as a referent may be active for one participant and inactive for another at the same time.

There's an obvious relation between the category of activation and the pragmatic functions Topic and Focus. In Lambrecht's model (1994: 115-116), which is an elaboration of Prince (1981), the activation states of referents are seen as preconditions for Topic and Focus functions. This is formalized in a Topic Acceptability Scale, which basically states that a referent can be coded as the topic of the sentence if it has a high degree of activation (Lambrecht 1994: 165):

\section{TOPIC ACCEPTABILITY SCALE}

Active
Accessible
Unused
Brand-new anchored
Brand-new unanchored
$\quad$ Table 1. Lambrecht's (1994) Topic Acceptability Scale

The Topic Acceptability Scale classifies referents according to their status in the ongoing discourse, and correlates this information with the likelihood for Topic and Focus function. Since the active/inactive status of a referent varies as the discourse unfolds, which referent is likely to receive Topic or Focus function in the grammatical representations is something which needs to be informed by the Contextual Component in accordance with the FDG approach to the relation between context and grammar.

Note, however, that the Topic Acceptability Scale merely indicates a general tendency in the assignment of pragmatic functions, but it does not describe a systematic process in the FDG sense discussed above, which also relates to the fact that pragmatic functions in FDG are intra-clausal notions. Thus, active referents can be focal, as in the following example:

\section{(2) A: Who thinks that? \\ B: I do}

B's answer contains a pronoun for a speech participant who is therefore necessarily active, but focal in the context of that particular interaction. Strictly speaking, then, the activation status of referents and its relation to the assignment of pragmatic functions is not a systematic correspondence, which would give support to the FDG approach to the grammar-context relation.

Note, furthermore, that in FDG, as well as in Lambrecht (1994), Topic is defined under the notion of aboutness. However, the cognitive category of activation seems to relate to that of givenness, rather than aboutness. As noted by Chafe (1994: 72), a given 
referent "can be characterized as already active at this point in the conversation" (emphasis in original). Undoubtedly, the categories of aboutness and givenness tend to overlap, as we usually talk about entities which are active or given in the context and for this reason activation may be seen as a precondition for Topic / Focus status. As mentioned earlier, though, it is possible for an active referent not to be the grammatical Topic of the sentence, which means that the two dimensions should be distinguished in the grammar. This coincides with Mackenzie and Keizer's (1991) view as presented above.

Mackenzie and Keizer (1991: 183) also note one additional problem in the characterization of the dimension of givenness: The fact that several different interpretations of givenness have been offered in the literature. They write

Thus, Given has been defined (in the narrowest sense) in terms of that which can be assumed to be in the consciousness of the addressee at the time of speaking (...). In a somewhat wider sense it includes that which is recoverable from the discourse (...), that which is activated in the discourse (...) or that which is discourse-bound (...). In its broadest sense, givenness is defined in terms of what is assumed to be part of knowledge shared by speaker and addressee (...).

Givenness can thus refer to the dynamic focussing on a referent in the interaction (narrow sense), or to the common (shared) knowledge of both the speaker and addressee at the time of speaking (broad sense).

It should also be noted that in the F(D)G tradition there's been much debate on the distinction between topicality/focality in discourse and the pragmatic functions Topic and Focus as sentence internal notions (see e.g. Bolkestein 1998). The reason may have been that authors were working under different assumptions of pragmatic relations based on either givenness or aboutness. In fact, Dik (1997a) made a clear distinction between D-topics, which refer to the entities the discourse is about, and S-topics, which refer to the entities the predication is about. ${ }^{6}$ Unfortunately, as Functional Grammar was never developed into a grammar for the analysis of discourse, the exact consequences of this distinction were not explored. The introduction of the notion of givenness in the grammar in a time dimension can thus help solve this problem and propose a more comprehensive treatment of pragmatic articulations in FDG. In the following section I will provide a couple of examples of the relevance of givenness to account for morphosyntactic processes.

\section{The grammar of givenness}

As mentioned earlier, the reason why givenness, and activation in particular, is not represented with specific operators or pragmatic functions at the Interpersonal Level in FDG is most likely due to the fact that it does not produce a systematic formal impact on linguistic expressions. This does not mean, however, that the active status of a referent does not tend to be coded through certain grammatical properties. Thus, Lambrecht (1994: 95) notes that the linguistic coding of active referents usually correlates with the following grammatical properties: Phonological attenuation and

\footnotetext{
${ }^{6}$ I am grateful to Evelien Keizer for reminding me of Dik's distinction.
} 
pronominal, inflectional and zero marking. However, these properties are not necessarily met in the coding of all active referents. Consider the following example:

(3) I met Peter and Bill yesterday. Bill has left his job.

Even though Peter and Bill are active referents the speaker uses a full proper noun in the second sentence which avoids the potential ambiguity of the pronominal expression 'he' in that context. This lack of systematic coding is noted by Lambrecht (1994: 108), who states that "an active referent may be coded as an unaccented or accented, pronominal or lexical, definite or indefinite expression, while a non-active (identifiable or unindentifiable referent) necessarily appears as an accented, lexical noun phrase which may be definite or indefinite." Crucially, then, inactiveness seems to correlate with accented and lexical expressions, which shows the relevance of the category at the Phonological Level and in lexical selection: If a referent is marked [active] at the Contextual Component its linguistic expression will necessarily be marked through [+accented] or fully lexical expressions.

Lambrecht also notes that there are syntactic correlates of activeness, although "these are not as easy to demonstrate". He claims that languages offer syntactic constructions whose role is to promote a referent to active status. These include leftdetachment constructions and presentative/existential sentences as in the following examples:

(4) a. My brother, he's a wonderful musician, you know

b. There's a new boy in town

What both constructions seem to have in common is the fact that they serve to introduce (or reintroduce) referents which are inactive (possibly to different degrees) in the discourse. In the case of presentative sentences, the referent 'a new boy' is assumed to be unidentifiable for the addressee, and becomes identifiable and active after being introduced in (4b). Left-detached constituents as in (4a) serve to reintroduce a typically inactive or merely semi-active referent.

The existence of these constructions proves that the grammar of languages provides means to introduce unidentifiable referents. In the same way as the Contextual Component should inform the grammar on the sex of the addressee in example (1) above, it should inform the grammar on the inactive status of the referents 'my brother' and 'a new boy' in the examples in (4). Hence, the selection of those referents for Orientation or Topic function can be accounted for under the FDG static 'informative' conception of the relation between context and grammar.

In the following subsections, however, I intend to demonstrate that certain syntactic operations are crucially sensitive to the dynamic construction of discourse and cannot be easily accommodated in the theory. The phenomena in question are subject and object raising and extraction of constituents from complex noun phrases. ${ }^{7}$ The former will illustrate the relevance of givenness under the narrow (activation) interpretation, whereas the latter will illustrate the relevance of givenness in the broad (shared) sense.

7 As pointed out to me by Francis Cornish (pc) there are also other construction types whose proper analysis would require recourse to contextual considerations. These include extraposition, the double-object construction and passivization. 


\subsection{Raising and activation}

The term 'raising' refers to a number of constructions in which a constituent within an embedded predication is morphosyntactically marked as either the subject or object of the matrix predication. Typical examples are offered in (5), (6) and (7):

(5) a. It seems that the children are allergic to something

b. The children seem to be allergic to something

(6) a. I believe that the children are allergic to something

b. I believe the children to be allergic to something

(7) a. It is difficult to please the children

b. The children are difficult to please

The examples in (5) illustrate subject raising: The italicised subject of the embedded clause in (5a) takes subject function of the matrix clause in (5b). Morphosyntactically, the children behaves as the subject of seem, as shown by the fact that both agree in number and that it takes preverbal position, which in English is usually reserved for subjects. Semantically, however, it is an argument of the embedded predicate, as it is the predication to be allergic to something that imposes semantic restrictions (e.g. animate) on the displaced subject.

The examples in (6) illustrate object raising. (6a) contains a that-complement clause which functions as the object of the predicate believe. In (6b), however, the subject of the complement clause takes object function. This can be easily proved by replacing the NP the children with a pronoun, in which case an accusative form would have to be employed: I believe them to be allergic to something. To avoid terminological confusions, $(5 \mathrm{~b})$ is also referred to as an instance of Subject-to-Subject Raising (SSR), whereas (6b) is also known as Subject-to-Object Raising (SOR).

Finally, the examples in (7) illustrate Object-to-Subject Raising (OSR), since the children in (7a) functions as the object of please and as the matrix subject in (7b). This paradigm is also known as 'tough-movement' in the generative tradition.

Most accounts of the processes, beginning with Postal's (1974) monograph, have concentrated primarily on the formal aspects of the constructions and on how to integrate the proposed analyses in syntactic theory. However, the relevance of discourse pragmatic notions in the analysis of raising has also been observed by a number of authors. Thus, Dik (1997b: 351) claims that "the displaced constituent must have a highly topical or focal status" and that the assignment of a pragmatic function "is what allows an embedded term to be raised into the matrix domain." Similarly, Givón (1984: 272) views raising as an operation which serves to increase the topicality of a referent. He notes that the raised NP is usually generic or definite, with indefinite referents giving rise to anomalous raising structures. The fact that raising usually operates on embedded subjects is understood as a restriction on the process, as only elements which already have some degree of topicality may be subject to further topicality increase. 
In García Velasco (2013) I have pursued this line of enquiry and shown that raising constructions serve to establish discourse cohesion by keeping a referent active. The following corpus example from Spanish illustrates this claim: ${ }^{8}$

(8) La representación del tiempo exige, sin embargo, un control cuidadoso del encuadre, de las condiciones de la escena, además del dominio de la problemática de la obturación. Lo que sigue recoge aspectos muy elusivos y sutiles que pueden quedarse en el capítulo de las intenciones pero que se pretende que acompañen a cada uno de los géneros. Así, el retrato parece que pretende condensar toda una vida en un segundo: la huella del tiempo. El paisaje parece que intenta convertir un segundo en un infinito: el tiempo acumulado. (...). El bodegón, por último, parece intentar que la apariencia estática de la escena (su aparente permanencia en el tiempo) se transmita como una ausencia de tiempo.

(Universo Fotográfico. Revista de Fotografía, nº 2, 05/2000)

The representation of time demands, however, a careful control of the frame, the scene conditions, as well as light-exposure. What follows captures the elusive and subtle aspects that might eventually turn out to be little more than aspirations, but which should accompany all genres. Thus, the portrait seems to capture a whole life in a second: the trace of time. The landscape seems to try to convert a second into the infinite: the cumulated time. (....) Still-life painting, finally, seems to intend that the static look of the scene be transmitted as the absence of time.

In this passage, a number of raising constructions with the verb parecer ('seem') ${ }^{9}$ serve to maintain textual cohesion. The text deals with the properties of the different photographic 'genres'. Each one of those (the portrait, the landscape and still-life) are subjects in the respective embedded predications, but are integrated in the matrix predications. The choice of a particular syntactic construction, then, is dynamically motivated by the needs of the text-creating activity, and thus confirms that the activation status of a referent is not only a precondition for the assignment of topic or focus status, but may be a goal in itself with a clear discourse function.

Similarly, several authors have argued that the use of SOR and OSR constructions in English is textually determined. Thus Noël (1997) claims that the choice between a that-complement clause and an infinitival clause after verbs such as believe depends upon the properties of the ongoing discourse. He notes that in $90 \%$ of the cases examined, the infinitival complement appears in contexts in which the referent of the raised NP has been previously mentioned (or is an inferable from a previously mentioned referent), as in the following example (the code refers to the British National Corpus): 10

(9) Hanson buys firms either because it believes them to be under-managed, or because it believes the firm's existing managers have over-extended themselves. (ABG2279)

8 Example taken from the CREA Corpus (REAL ACADEMIA ESPAÑOLA: Banco de datos (CREA) [online version]. Corpus de referencia del español actual. http://corpus.rae.es/creanet.html.

9. Note, however, that the first two instances of 'parecer' in the text do not combine with infinitival embedded predications and, hence, might not be considered true cases of syntactic raising, but of leftdislocated structures. In any event, this would confirm that subject raising serves an activation role similar to those. See García Velasco (2013) for further discussion.

10 But obviously, this does not mean that all active referents coded in embedded subjects should undergo the raising process, as the second conjunct in the example shows. 
Further evidence is obtained from OSR in English. Postal (1974) noted that raised objects cannot be non-referential or indefinite (i.e. they must be given in discourse). The fact that noun phrases which have a definite unique function are much easier to raise is easy to demonstrate:

(10) a. It was easy to talk to someone / John

b. John / *Someone was easy to talk to

However, Mair (1990) notes that, although this is an important tendency, it is certainly possible to have indefinite raised subjects. Therefore, he argues, there must be other tendencies which also favour the use of the construction. Among those he cites the need to relieve syntactic complexity at the end of the clause and achieve a more balanced structure, and again textual cohesion, as in the following example in which the raised subject refers to an already mentioned referent (Mair 1990: 68):

(11) These nerves follow the same plan as those gnathestomes but they are difficult to make out by dissection in the lamprey

Mair (1990: 71) concludes that OSR "is a topic creating mechanism, strengthening ties of syntactic cohesion across sentences." (emphasis in original).

If Noël and Mair's observations are correct, then activation, through raising constructions, has a clear impact on the establishment of discourse cohesion even if the selection of a raised construction is not a systematic option in the sense discussed in section 2. But if one is to exclude the relevance of activation in an account of raising on the grounds that speakers are not forced to choose a raised construction whenever certain pragmatic properties are met, then our understanding of the process will only be partial. Consequently, the introduction of activation as a separate pragmatic dimension with relevance to the dynamic construction of discourse contributes to offering a more comprehensive picture of language use.

\subsection{Extraction from complex noun phrases: Sharedness}

In García Velasco (2008) I showed that the displacement of constituents from complex noun phrases is also connected to the pragmatic status of both the displaced unit and the extracting domain. ${ }^{11}$ The original problem was put forward by John Ross and has spurred an enormous amount of research in the generative tradition. The following are Ross's examples:

(12) a. I believed [s that Otto was wearing this hat].

b. The hat which I believed [s that Otto was wearing __ ] is red.

(13) a. I believed [NP the claim [s that Otto was wearing this hat].

b. * The hat which I believed [NP the claim [s that Otto was wearing __ ] ] is red.

As noted by Ross, these sentences differ only in that the clausal complement of believe is embedded in an NP headed by claim in (13a), but not in (12a). This difference

\footnotetext{
11 See Goldberg (2006: Chapter 7) for an analysis of displacement constraints along similar lines.
} 
must then be behind the fact that the complement of the verb wear can be displaced in (12b) but not in the corresponding (13b). A similar situation obtains if the clausal constituent is not a complement but a relative clause, as in example (15a). As relative clauses are necessarily embedded within NPs, extraction appears to be blocked, as shown in (15b) (Ross 1986 [1967]: 71):

(14) a. I read [NP a statement about that man].

b. The man who I read [NP a statement about___ ] is sick.

(15) a. I read [NP a statement [s which was about that man]].

b. * The man who I read [NP a statement [s which was about _ ] ] is sick.

Questioning elements in these syntactic contexts also yields unacceptable sentences:

(16) a. I believe [NP the claim [s that Otto was wearing a hat]].

b. * What did you believe [NP the claim [s that Otto was wearing __ ] ]?

(17) a. I read [NP a statement [s which was about Peter]].

b. * Who did you read [NP a statement [s which was about __ ] ]?

These facts led Ross to propose the following principle (1986: 76), which he named The Complex Noun Phrase Constraint (CNPC):

The Complex NP Constraint (CNPC)

No element contained in a sentence dominated by a noun phrase with a lexical head noun may be moved out of that noun phrase by a transformation.

The CNPC thus relies on a definition of the complex NP as a syntactic 'island' from which extraction is impossible. Complex NPs are headed by a noun which dominates a clausal constituent which may be either a complement to the head noun or a relative clause. The nouns that can take clausal complements in English are typically derived from verbal predicates (belief, knowledge, eagerness, etc.) as well as a few other items such as fact, idea or rumour. It is interesting to observe that nouns like fact and idea introduce a referent which can be definite on first mentioning (J. Rijkhoff, pc). The role of the complement is to anchor (see Prince 1981) the specific referent for the noun so that it becomes identifiable for the addressee. Similarly, Rijkhoff (2002: 177) notes that restrictive relative clauses typically serve a localizing function, as they express the situation in which the head NP participates and therefore localize it in time or cognitive space. This explains why the typical relative clause modifies a definite noun and, in many languages, this seems to be the only possibility. This means that both complement clauses and restrictive relative clauses typically, though not necessarily always, contain shared, presupposed knowledge, since the information they provide is necessary to locate or identify the referent of the head noun.

As mentioned earlier, some constructions serve to activate a referent which is consequently assumed to be inactive at the moment the speech act takes place. At the same time, if a constituent is assigned a special pragmatic status within an utterance, it is to be expected that the extracting domain in the expression should contain presupposed information. Thus, in (13) the sequence that Otto was wearing this hat contributes to identifying the referent of the claim and it must necessarily be understood 
as shared knowledge. Promoting this hat to active status is communicatively anomalous and incompatible with the role of the complement clause as an anchoring unit. Goldberg (2006: 135) has formalized this idea with the following generalization:

The BCI

Backgrounded constructions are islands

The motivation for this principle is also assumed to rely on discourse factors. Goldberg (2006: 135) claims that it "is pragmatically anomalous to treat an element as at once backgrounded and discourse-prominent". Backgrounded elements are constituents which are neither topic nor part of the potential focus domain of the utterance, that is, the part of the sentence which is being asserted. Presupposed information is backgrounded, which can be demonstrated by the fact that it remains implicit in both the negative and positive forms of the sentence. Thus, Goldberg (2006: 134) argues, negating the matrix clause in an example like (16a) (I didn't believe the claim that Otto was wearing a hat) does not negate the presupposed information 'Otto was wearing a hat', which explains which the hat cannot be relativized or questioned.

The analysis of wh-question formation goes along similar lines. A wh-question promotes the referent of the interrogative element to active status. The problem relates to the previous discussion: The constituents present in the complement or relative clause typically encode shared knowledge which serves to identify the referent of the head noun. Therefore, questioning one of them seems pragmatically awkward. It would be impossible to identify the referent of the head noun of the complex NP if the sequence used for that purpose (i.e. the complement/relative clause) contains an unidentified referent itself.

If this analysis is correct, then the use of the notions activation and sharedness offers an important insight into the syntactic properties of languages. Note that the same restriction, the fact that constituents within units containing presupposed or shared information cannot be displaced, seems to apply equally to the processes of topicalization and focalization, which means that pragmatic functions are not sufficient to explain the problem. The combination of activation and sharedness not only explains which displaced configurations are possible, but also which ones are not permitted in the English language. However, as their relevance in the dynamic construction of discourse does not correlate with systematic formal impact in the grammar they cannot be captured in the static form-oriented relation between context and grammar which is defended in FDG.

\section{Some (preliminary) implications for FDG}

The purpose of the previous sections has been to show that certain grammatical processes can only be fully understood if reference is made to the dynamic construction of the discourse. Activation and sharedness have been understood here as mental notions which serve to focus the speech participants' attention on specific entities / pieces of information and common knowledge. The obvious question is how these two notions and the general dimension of givenness can be incorporated into FDG.

The most immediate option would seem to follow Lambrecht's idea that activation serves as a precondition for Topic status and assume that the givenness status 
of referents should be specified in the Contextual Component, which would in turn inform the grammar for the purposes of pragmatic function assignment. There are two reasons why this analysis does not seem adequate. First, as argued in the preceding sections, the relevance of the Contextual Component in the construction of linguistic expressions is mediated by the mental representations which the speech participants construct. Given that those mental models are necessarily private, the Contextual Component in FDG cannot represent both the speaker's and the addressee's states at the same time, unless the theory assumes that the Contextual Component only represents shared knowledge as in Mackenzie's (2012; this issue) proposal of a dialogic FDG. Note, however, that Mackenzie assumes that his dialogic Contextual Component is 'public' and contains 'implicit common ground' which is constructed cooperatively by the interlocutors in the interaction. ${ }^{12}$

The mental context, understood as the speech participants' grasp of the objective Contextual Component, can be easily incorporated into FDG if we assume that the generation of a linguistic expression begins with a communicative intention which is constructed on the basis of a mental representation of the setting, which is in turn created on the basis of information stemming from the surrounding discoursal and situational context. ${ }^{13}$ This is indicated in the following figure (see Hengeveld and Mackenzie 2008: 6), by means of an arrow connecting the Contextual and Conceptual components, which contains a box representing the private mental context:

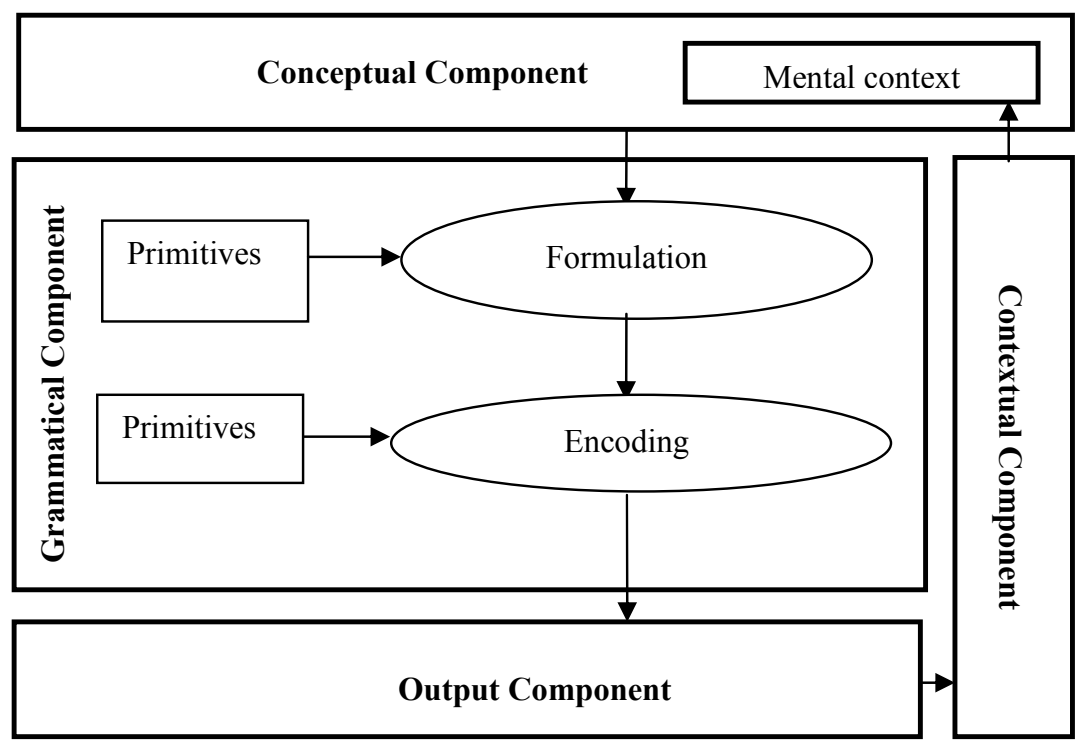

Figure 1: The relation between the Contextual and Conceptual components in FDG

12 A number of participants in the Barcelona workshop have pointed out to me the difficulty in integrating the notion of sharedness in the model if the Contextual Component is assumed to be a private mental entity. A possible solution to this problem was also given by another participant, who suggested that shared knowledge could be represented as an area of overlap between the participants' Conceptual Components, which would also contain the participants' mental representation of the co-constructed common ground in Mackenzie's proposal.

13 One theoretical consequence of this move is that FDG becomes a model of the Natural Language User against the view defended by its proponents as a pattern model of encoded intentions. I owe this observation to Francis Cornish. 
The Conceptual Component should thus contain the participants' mental context which would be constantly updated on the basis of the information provided by the Contextual Component as the interaction evolves.

This proposal, however, poses a number of interesting questions on the general organization of FDG. It presupposes the existence of two contexts, an objective context and a subjective representation of it. I have argued that it is only the latter that counts for linguistic usage, so that the right-hand box containing the objective Contextual Component might in principle be eliminated as it is not relevant in grammatical analysis. However, in a dynamic interpretation of linguistic interaction the objective context is fed with linguistic information from previous utterances and with nonlinguistic information if the setting is modified during the interaction. This obviously may have an impact on the participants' mental context. This is indicated in the figure with an arrow connecting the Output and Contextual Components. Finally, given that context can only influence grammar through the speaker's mental representations, the original arrows connecting Formulation and Encoding with the Contextual Component are eliminated.

Interestingly, this proposal corresponds nicely to Cornish's (2009) distinction between Text, Context and Discourse. Roughly, the Text is the product of the Output Component, whereas the Context includes the "domain of reference of a given text, the co-text, the genre of speech event in progress, the discourse constructed upstream, the socio-cultural environment assumed by the text, and the specific utterance situation at hand [and] is subject to a continuous process of construction and revision as the discourse unfolds." (Cornish 2009: 99). Finally, Cornish's Discourse "refers to the hierarchically structured, mentally represented product of the sequence of utterance, propositional, illocutionary and indexical acts that the participants are jointly carrying out as the communication unfolds" (99-100). This characterization of discourse emphasizes its mental nature and its status as a cooperatively created product, both of which are essential features of the notion of mental context employed here.

A second problem in the characterization of givenness as a precondition for pragmatic function assignment relates to the theory's own treatment of pragmatic functions. In accordance with the static form-oriented approach of the grammar component FDG argues that the assignment of pragmatic functions is only relevant in the grammar if it has a formal impact, that is, if the language in question shows any kind of grammatical output which can only be attributed to the systematic assignment of a pragmatic function. Obviously, this is not the case with either raising or extraction processes as their application to active or presupposed entities is not obligatory.

It is interesting at this point to review the treatment of information structure in current FDG. As shown in Hengeveld and Mackenzie (2008) the theory offers an approach to pragmatic functions which arranges them along three different dimensions:

(18) Focus (vs. background)

Topic (vs. comment)

Contrast (vs. overlap)

Subacts (SA) of ascription and reference may be assigned Pragmatic Functions at the Interpersonal Level. The different combinations of pragmatic functions and SAs are named content frames, which correspond to familiar information structure configurations such as those in (19): 
(19) Thetic

$\left[(\mathrm{SA})^{\mathrm{N}}\right]_{\mathrm{FOC}}$

Categorical

$\left[(\mathrm{SA})_{\text {TOP }}(\mathrm{SA})^{\mathrm{N}}(\mathrm{SA})_{\mathrm{FOC}}\right]$

Presentative

$$
\left[(\mathrm{SA})^{\mathrm{N}}(\mathrm{SA})_{\text {TOPFOC }}\right]
$$

Hengeveld and Mackenzie add that these frames are language specific and can take different forms in different languages. Thus, Categorical Frames in Topic-oriented languages take the form in (20a), whereas in Focus-oriented languages they take the form in (20b):

(20) a. $\left[(\mathrm{SA})^{\mathrm{N}}(\mathrm{SA})_{\mathrm{TOP}}\right]$

b. $\left[(\mathrm{SA})^{\mathrm{N}}(\mathrm{SA})_{\mathrm{FOC}}\right]$

The obvious consequence of the FDG approach is that these articulations can only be identified if Topic and Focus receive formal systematic treatment in the utterance. As mentioned earlier, Topic in FDG is defined in terms of the notion of aboutness in the Discourse Act and not in terms of the notion of continuity in discourse, topicality or givenness, which is natural, given the fact that topical or thematic continuity can only be studied if long stretches of discourse are analysed, rather than the formal properties of isolated Discourse Acts.

In the previous sections I have argued that the structure and organization of discourse is sensitive to a second pragmatic dimension which I described in terms of the notion of givenness. Given that this dimension does not seem to correlate with systematic effects in the grammar, its relevance in the structural analysis of individual sentences is limited. However, continued topics, as Erteschik-Shir (2007: 10) calls them, can also be relevant in certain grammatical processes. Thus, following Vallduví (1993), Erteschik-Shir (2007: 10) notes that in Catalan only 'switch' or 'shifted' topics can be fronted, whereas continued topics cannot. The reason is that shifted topics introduce a "change of address" and this excludes continued topics, which are active in discourse. Now, if language systems are sensitive to the topical nature of a particular unit, the FDG approach faces a fundamental problem, for the same pragmatic function Topic might be assigned to entities with different pragmatic properties across languages.

A solution to this problem might be found if, together with 'aboutness-Topic', a second type of Topic is introduced in FDG, defined in terms of givenness. Whereas the prominence / aboutness articulation would correspond to the pragmatic structuring of individual utterances, the time / givenness articulation would relate to the pragmatic structuring of discourse and would respond to a dynamic temporal dimension as opposed to the static form-oriented nature of aboutness. It is thus possible to add two new configurations of pragmatic functions to the FDG inventory; this would lead to the following picture:

Time dimension: givenness

Active (vs. inactive)

Shared (vs. unshared) 


\section{Prominence dimension: aboutness \\ Focus (vs. background) \\ Topic (vs. comment) \\ Contrast (vs. overlap)}

The time dimension would relate to the mental states of the speech participants and the text creating activity, whereas the prominence dimension would relate to the actual impact on the grammar's characterization of individual sentences. Undoubtedly, both dimensions interact in rather complex ways, but it is useful to understand that they are essentially of a different nature and that certain grammatical processes may respond to the needs of the dynamic discourse construction and others to choices forced by the grammar of languages. ${ }^{14}$

In García Velasco (2013) I argued that the aboutness dimension serves to single out referents for special pragmatic status, whereas the givenness dimension tends to organize discourse in the most efficient and natural way, which accounts for the typical lack of grammatical coding in this dimension. In that paper I introduced the notion of Marked and Unmarked Pragmatic Articulations:

\section{(i) Marked Pragmatic Articulations (MPA)}

A marked pragmatic articulation corresponds to a pragmatic structuring of linguistic expressions in which a referent is assigned a special prominent status.

Marked Pragmatic Articulations correlate with special pragmatic treatment which deviates from natural morphosyntactic or prosodic coding.

Marked Pragmatic Articulations operate on the distribution of Topical and Focal Information.

\section{(ii) Unmarked Pragmatic Articulations (UPA)}

Unmarked pragmatic articulations correspond to a neutral pragmatic structuring of linguistic expressions and are therefore the most efficient articulations to establish textual cohesion, and thematic and referential continuity.

Unmarked Pragmatic Articulations correlate with the basic morphosyntactic and prosodic properties of the language.

Unmarked pragmatic articulations operate on the distribution of Given and New information.

MPAs would thus be the result of the assignment of Pragmatic Functions at the Interpersonal Level, whereas UPAs would not and would instead be directly coded in Content Frames. They would thus not result from the combinations of Subacts and pragmatic functions, but should be understood as the default distribution of information in languages when no other measures are taken. Hence, the tendency for raising to operate on embedded subjects, which are subsequently promoted to main clause

14 It might seem that the notions of identifiability and sharedness apply to the same entities, as identifiable referents are those which the speaker assumes to be shared by the speech participants. This redundancy, however, vanishes if one assumes a dynamic interpretation of the notion sharedness. In much the same way as a referent can be active at some point in the interaction, a referent can be characterized as shared at a point in the interaction along the time dimension. In other words, a shared entity is selected as such for the purposes of the text creating activity among the participants' common ground of knowledge or set of identifiable referents. 


\section{Daniel García Velasco}

subjects, would be a consequence of the need for placing active referents in a natural syntactic position for given information. From a psycholinguistic perspective, it is expected that UPAs facilitate processing and this is precisely argued for in Davison (1984). She notes that the Subject function marks a constituent as a Topic, only in the absence of stronger indications of topicality, and that the "processing of a sentence is facilitated if some element in it can be linked with an antecedent in context" (Davison 1984: 802). This also supports the idea that UPAs are efficient configurations which are favoured in the grammar of languages and upon which the assignment of pragmatic functions may further operate.

\section{Conclusion}

In this paper, I have tried to demonstrate that the notion of givenness (in close relation with that of activation) should be incorporated in FDG as another dimension of pragmatic organization which is relevant in the structuring of discourse rather than the individual sentence. I have illustrated this proposal with the study of two syntactic phenomena, raising and extraction from complex noun phrases, for which an analysis based on pragmatic functions as currently understood in FDG does not seem to be sufficient. Finally, I have proposed to integrate the analysis in FDG by distinguishing marked from unmarked pragmatic articulations, with only the former being sensitive to the assignment of pragmatic functions along the prominence dimension.

Of course, there are a number of issues which still require further research. These include a comparison of the differences between this proposal and Keizer's (this issue) multi-factor approach to activation; a more detailed analysis of activation and its relation with identifiability and other pragmatic categories, and with the other levels in the grammar component. Hopefully, the study of those aspects will serve to confirm that the approach defended here is on the right track.

\section{References}

Bolkestein, A. Machtelt (1998) What to do with Topic and Focus? Evaluating pragmatic information. In Mike Hannay, and A. Machtelt Bolkestein (eds.), Functional Grammar and Verbal Interaction. Amsterdam/Philadelphia: John Benjamins Publishing Company, pp. 193-214.

Butler, Christopher S. (2008) Interpersonal meaning in the noun phrase. In Jan Rijkhoff, and Daniel García Velascol (eds.), The Noun Phrase in Functional Discourse Grammar. Berlin: Mouton de Gruyter, pp. 221-261.

Butler, Christopher S. (2013) A reappraisal of the functional enterprise, with particular reference to Functional Discourse Grammar. Revista Canaria de Estudios Ingleses 67: 13-42.

Chafe, Wallace (1994) Discourse, Consciousness and Time. Chicago: The University of Chicago Press.

Connolly, John H. (2007) Context in Functional Discourse Grammar. Alfa 51: 11-33.

Connolly, John H (this issue) The contextual component within a dynamic implementation of the FDG model: Structure and interaction. Pragmatics 24:2. 229-248. 
Cornish, Francis (2009) Text and discourse as context: Discourse anaphora and the FDG contextual component. In Evelien Keizer, and Gerry Wanders (eds.), Special Issue: The London papers I. Web Papers in Functional Discourse Grammar, pp. 97-115.

Davison, Alice (1984) Syntactic markedness and the definition of sentence topic. Language 60: 797-846.

Dik, Simon C. (1997a) The Theory of Functional Grammar. Part 1. The Structure of the Clause. [Kees Hengeveld (ed.)]. Berlin: Mouton de Gruyter.

Dik, Simon C. (1997b) The Theory of Functional Grammar. Part 2. Complex and Derived Constructions. [Kees Hengeveld (ed.)]. Berlin: Mouton de Gruyter.

Erteschik-Shir, Nomi (2007) Information Structure. Oxford: Oxford University Press.

García Velasco, Daniel (2008) Functional Discourse Grammar and extraction from (complex) noun phrases. In Jan Rijkhoff, and Daniel García Velasco (eds.), The Noun Phrase in Functional Discourse Grammar. Berlin: Mouton de Gruyter, pp. 321-363.

García Velasco, Daniel (2013) Raising in Functional Discourse Grammar. In J. Lachlan Mackenzie, and Hella Olbertz (eds.), Casebook in Functional Discourse Grammar. Amsterdam: John Benjamins Publishing Company, pp. 249-276.

Givón, Talmy (1984) Syntax: A functional-typological introduction. Volume II. Amsterdam: John Benjamins Publishing Company.

Goldberg, Adele E. (2006) Constructions at Work. Oxford: Oxford University Press.

Hengeveld, Kees (2004) Epilogue. In J. Lachlan Mackenzie, and María Ángeles Gómez González (eds.), A New Architecture for Functional Grammar. Berlin/New York: Mouton de Gruyter, pp. 365-378.

Hengeveld, Kees, and J. Lachlan Mackenzie (2008) Functional Discourse Grammar. Oxford: Oxford University Press.

Hengeveld, Kees, and J. Lachlan Mackenzie (this issue) Grammar and context in Functional Discourse Grammar. Pragmatics 24.2: 203-227.

Keizer, Evelien (this issue) Context and cognition in FDG: What, where and why? Pragmatics 24.2: 399423.

Lambrecht, Knud (1994) Information Structure and Sentence Form. Cambridge: Cambridge University Press.

Mackenzie, J. Lachlan (2012) Cognitive adequacy in a dialogic Functional Discourse Grammar. Language Sciences 34: 421-432.

Mackenzie, J. Lachlan (this issue) The Contextual Component in a dialogic FDG. Pragmatics 24.2: 249273.

Mackenzie, J. Lachlan, and Evelien Keizer (1991) On assigning pragmatic functions in English. Pragmatics 1: 169-215.

Mair, Christian (1990) Infinitival complement clauses in English. Cambridge: Cambridge University Press.

Noël, Dirk (1997) The choice between infinitives and that-clauses after believe. English Language and Linguistics 1: 271-284. 


\section{Daniel García Velasco}

Postal, Paul M. (1974) On Raising. One rule of English grammar and its theoretical implications. Cambridge, Massachusetts: The MIT Press.

Prince, Ellen F. (1981) Toward a taxonomy of given-new information. In P. Cole (ed.), Radical Pragmatics. New York: Academic Press, pp. 223-256.

Ross, John R. (1986) [1967] Infinite Syntax. Norwood: Ablex Publishing Company. First published as Constraints on variables in Syntax. Ph.D. dissertation, MIT.

Smit, Niels (2007) Information packaging in Functional Discourse Grammar. Alfa: Revista de Lingüística 51: 91-118.

Vallduví, E. (1993) The Informational Component. Standford: CSLI Dissertations.

DANIEL GARCÍA VELASCO, Ph.D., is Senior Lecturer in English Linguistics at the University of Oviedo, Spain, where he teaches courses on syntax, lexicology and semantics from both a functional and a formalist perspective. He is an active researcher in Functional Discourse Grammar and has contributed to the development of the theory in different areas. In 2002, together with Kees Hengeveld (University of Amsterdam, The Netherlands), he published "Do we need predicate frames?" (Mairal Usón, R. and Pérez Quintero, M.J. (eds), New Perspectives on Argument Structure in Functional Grammar, Berlin, Mouton de Gruyter) an article in which the authors propose to separate lexemes from the frames in which they appear in the lexicon and dispense with the notion of "predicate frame". More recently, he has proposed a new approach to the semantics of lexical items with significant consequences for the organization of the lexicon in Functional Discourse Grammar ("Lexical Competence and Functional Discourse Grammar". Alfa - Revista de Lingüística 51). The adequacy of this proposal has been tested in the article "Conversion in English and its implications for Functional Discourse Grammar", Lingua, 2009). He has also co-edited the volume The Noun Phrase in Functional Discourse Grammar (Berlin, Mouton de Gruyter), together with Jan Rijkhoff (University of Aarhus, Denmark). This book contains a contribution by Daniel García Velasco ("Functional Discourse Grammar and extraction from (complex) noun phrases"), in which the author offers a pragmatic-based approach to Ross's Complex Noun Phrase Constraint. Together with Gerry Wanders, he has edited a special issue of Language Sciences on the Morphosyntactic Level in Functional Discourse Grammar. (Language Sciences 34, 2012.) His current interests include syntactic displacement and the representation of lexical knowledge in functional models of language.

Address: Universidad de Oviedo. Departamento de Filología Anglogermánica y Francesa. Teniente Alfonso Martínez s/n., 33011 Oviedo, Spain. E-mail: danielg@uniovi.es 